\title{
Research on Deformation Behaviors and Surface Quality Model at High-speed Cutting
}

\author{
H.P. An ${ }^{\text {a1, } 2^{*}}$, Z.Y. Rui ${ }^{\text {b2 }}$, J.F. Guo ${ }^{2}$ \\ ${ }^{1}$ College of BaiLei Mechanical Engineering, Lan Zhou City University, Lanzhou 730070, China \\ ${ }^{2}$ College of Mechano-Electronic Engineering, Lanzhou Univ. of Tech., Lanzhou 730050, China \\ ahp2004@126.com \\ ${ }^{*}$ Corresponding author
}

Keywords: ZGMn13 Steel, High-speed Cutting, Deformation Behavior, Surface Quality, Prediction Model.

\begin{abstract}
The cemented carbide cutting tools were experimentally performed to dry cut high manganese steel (ZG Mn13) at high speed, and the high-speed cutting behaviors and the effect of cutting parameters on cutting quality were investigated, and predict model of surface roughness for high-speed cutting was established. The results show that the surface roughness first increases and then decreases with the cutting speed increase and feed rates decrease, and finally trends to be stable; the surface quality of high-speed cutting is obviously superior to that of conventional cutting. From the macro-graphs and micro-graphs of chips, the chips shows continuous belt-shaped macroscopic appearances, whereas the top surface of the chips reveals jagged microscopic characteristics, with burn and adhesion shear characteristics on the bottom surface. Work hardening and high-temperature softening simultaneously affect the shear deformation. When the effect of the former is dominant, the belt-shape characteristics are visible; when the effect of the latter is dominant, the jagged characteristics are notable and the belt-shape characteristics are weak. This indicates that the adiabatic shear slip occurs. The cutting parameters are reasonably selected to obtain ideal cutting quality and chip shape. The predicted model of the surface roughness provides an important reference for the surface cutting quality of high-speed cutting or the selection of cutting parameters according to cutting quality.
\end{abstract}

\section{Introduction}

High manganese steels show high impact toughness and work hardening caused by heavy impact loads, which have been widely applied in engineering machinery due to high wear resistance [1]. However, high manganese concentration (mass proportion of $11 \% \sim 14 \%$ ) results in higher strength, fracture toughness and bigger elongation, as well as lower thermal conductivity. Therefore, the high manganese steels are difficultly machined due to high cutting force and cutting temperature, and continuous chips result in low cutting lifetimes due to severe adhesion wear. The cutting speed of the cemented carbide cutting tools for cutting high manganese steels is more than $30 \mathrm{~m} / \mathrm{min}[2]$. Therefore, poor workability is an important reason for the cutting efficiency and quality of the high manganese steel materials. Meanwhile, longer continuous chips affect cutting process and operation safety. In addition, high cutting temperature accelerates the wear of the cutting tools, decreases its lifetime and increases the auxiliary time of tool replacement and cost. Recently, the investigations of high-speed cutting are concentrated on some difficult cutting materials such as titanium alloys, hardened steels and high temperature alloys. Advanced cutting tools have been produced by the cemented carbides, polycrystalline cubic boron nitride and diamond cutting tools materials [4-6]. The hardness of metal ceramic cutting tools is higher than that of cemented carbide cutting tools, but the latter shows a better fracture toughness. However, the metal ceramic cutting tools show better comprehensive properties. According to the definition of high-speed cutting, the cutting speeds which are about 5 10 times than conventional cutting speed are defined as high-speed cutting. The real high temperature and adiabatic shear of deformation zones caused by quick cutting lead to the material softening, and further result in notable changes in high-speed cutting 
mechanisms, and significantly affect the cutting performance. Meanwhile, the cutting chips with fast flowing speeds take away most of the cutting heat during the high-speed cutting[7-10], and notably decrease the temperature of the secondary deformation zone, which is available to improve the lifespan of the cutting tools. The quality model of high-speed cutting is a key to theoretically research of high-speed cutting technology [11-15], and provides important significance for the prediction of cutting quality and determination of cutting parameters.

In the present work, taking the high manganese steel with strong work hardening for example, the metal ceramic cutting tools were experimentally carried out for high-speed dry cutting. We investigated the effects of the cutting speeds and feed rates on cutting quality and material deformation, and established the prediction model of roughness, and finally obtained optimized cutting parameters.

\section{Cutting Experiment}

\section{Experimental Conditions}

A CAK6150Dj lathe was performed for high-speed cutting experiment, and Fig.1 shows the experimental testing system. A digital roughness tester made in Japan was used to measure the surface roughness.

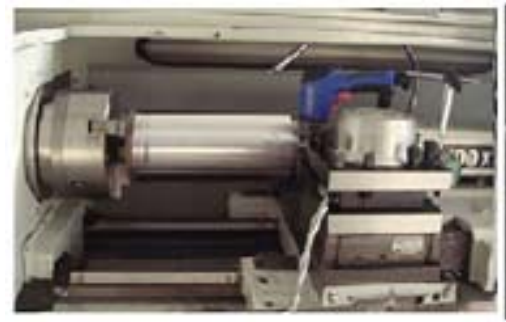

Fig. 1 Cutting test site

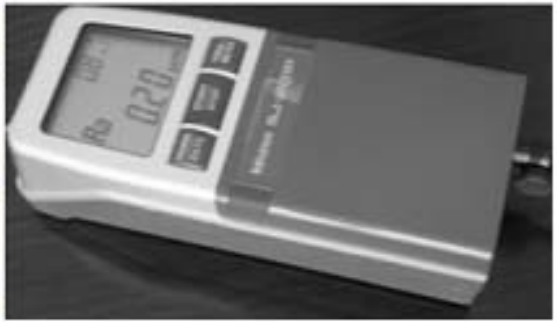

Fig. 2 Digital roughness tester

\section{Material and Fixed Method}

High manganese steel pipe (ZGMn 13) was selected for experimental material, with a dimension of $\varphi 168 \times 330$ and a thickness of $20 \mathrm{~mm}$. Chemical composition is shown in Table 1 .

Table 1 Chemical compositions of high manganese steel (wt. \%)

\begin{tabular}{c|ccccc}
\hline Chemical composition & $\mathrm{Mn}$ & $\mathrm{C}$ & $\mathrm{Si}$ & $\mathrm{P}$ & $\mathrm{S}$ \\
\hline Concentration $/ \%$ & $11 \sim 14$ & $1.0 \sim 1.4$ & $0.3 \sim 1.0$ & $<0.03$ & $<0.05$ \\
\hline
\end{tabular}

During the installation of experimental samples, standard accessories consisted of three jaw chucks, a specially designed plug and the tip were adopted to achieve the installing way of one clip one tip. Indexable turning represents pecial tool bars, which was applied in the cutting tools, and piezoelectric crystal sensor and measuring system were installed in cutting tools.

1.3 Tool composition, performance and geometric parameters

Metal ceramic blades (Ningbo Ceramic Technology Co., Ltd.) were used in present work. The grade of blades is RCHT01, and model is SNMN150716. Tool material is composed of $\mathrm{TiCN}_{1} \mathrm{Al}_{2} \mathrm{O}_{3}$, $\mathrm{Ni}$ and Mo. The tensile strength $\left(\sigma_{\mathrm{b}}\right)$ ranges from 700 to $1000 \mathrm{MPa}$, and hardness is in the range of 93 95HRA; The grade of blades is SNMN150716, and tool material is composed of TiCN, WC, $\mathrm{MoC}$, Ni and Co. The tensile strength $\left(\sigma_{\mathrm{b}}\right)$ ranges from 1000 to $1800 \mathrm{MPa}$, and hardness is in the range of 91 94HRA. Tool geometric parameters are shown in Table 2. 
Table 2 Effective Parameters of Metal Ceramic Cutting Tools

\begin{tabular}{ccccccccc}
\hline $\mathrm{k}_{\mathrm{r}}$ & $\mathrm{k}_{\mathrm{r}}^{\prime}$ & $\gamma_{\mathrm{o}}$ & $\gamma_{\mathrm{o}}^{\prime}$ & $\alpha_{\mathrm{o}}$ & $\Lambda \mathrm{s}$ & $r_{\varepsilon}$ & Chamfer angle \\
$\left.\gamma^{\circ}\right)$ & $/\left(^{\circ}\right)$ & $/\left(^{\circ}\right)$ & $\left./{ }^{\circ}\right)$ & $\left(^{\circ}\right)$ & $/\left(^{\circ}\right)$ & $\begin{array}{c}\text { Chamfer width } \\
/(\mathrm{mm})\end{array}$ & $\mathrm{b}_{\mathrm{o} 1} /(\mathrm{mm})$ \\
\hline 65 & 25 & 0 & 0 & 0 & 0 & 1.6 & 30 & 0.3 \\
\hline
\end{tabular}

\section{The Selection of Cutting Parameter and Roughness Measurement}

In this test, the materials with relative big diameters were experimentally used to control linear speed to reach high-speed conditions. The cutting parameters and surface roughness are shown in Table 3. For conventional cutting, the cutting speed $\left(\mathrm{v}_{\mathrm{c}}\right)$ of cemented carbide cutting tools for high manganese steels is no more than $30 \mathrm{~m} / \mathrm{min}$, whereas the cutting speed of the high-speed cutting is $5 \sim 10$ times of the conventional cutting speeds. Therefore, the cutting speeds in the present work are in the range of high-speed cutting speeds. According to the relationship between the feed speeds $\left(50,100,150,200\right.$ and $250 \mathrm{~mm} / \mathrm{min}$, respectively) and spindle speeds as follows: $\mathrm{f}=\mathrm{v}_{\mathrm{f}} / \mathrm{n}$, feed rates in Table 3 can be calculated. According to the theory of metal cutting, in the three cutting factors, the effect of back cutting depth on surface quality is limit. In order to decrease workloads, the back cutting depth is constant in the present work.

Table 3 Experimental cutting parameters and surface roughness values

\begin{tabular}{ccccc}
\hline Number & Cutting speed, $\mathrm{v}_{\mathrm{c}} /(\mathrm{m} / \mathrm{min})$ & $\begin{array}{c}\text { Feed rate, } \mathrm{f} / \\
(\mathrm{mm} / \mathrm{r})\end{array}$ & Cutting depth, $\mathrm{a}_{\mathrm{p}} /(\mathrm{mm})$ & roughness, Ra/ $(\mu \mathrm{m})$ \\
\hline 1 & 258.2 & 0.1 & & 0.92 \\
2 & 409.3 & 0.063 & 0.15 & 2.35 \\
3 & 507 & 0.05 & & 1.4 \\
4 & 602.7 & 0.042 & 2.25 \\
5 & 746.3 & 0.033 & 1.54 \\
\hline
\end{tabular}

Surface roughness values were measured by digital roughness tester, left, intermediate and right points along the length direction of the machined surface were measured and recorded, and each roughness value is the average value of three measured values of each point. Digital roughness tester is shown in Fig. 2.

Table 3 shows the cutting of each zone, were the samples measured, calculating the average value of the three points.

\section{Results and Discussion}

\section{The Effect of Cutting Dosage on Surface Quality}

The experimental samples are divided into several groups, and measured surface roughness values as shown in Fig.3. Each test group lists the cutting parameters and the corresponding surface roughness value. As shown in Fig.3, under high-speed cutting speeds, the surface roughness values of high manganese steel show wave-like changes, with a low amplitude. The overall variation is that the surface roughness values first increase and then decrease with the cutting speeds increase and feed rates decrease, but final variable trend gradually decreases, and the surface quality gradually improved. In the present work, only cutting speeds and feed rates are considered, and the best surface quality corresponding to reasonable matching values of cutting dosage for the high-speed cutting of high manganese steel can be directly observed from the bar graphs. The cutting parameters of the group 1 are: a cutting speed of $258.2 \mathrm{~m} / \mathrm{min}$, a feed rate of $0.01 \mathrm{~m} / \mathrm{r}$ and a 
cutting depth of $0.15 \mathrm{~mm}$; the cutting parameters of the group 3 are: a cutting speed of $507 \mathrm{~m} / \mathrm{min}$, a feed rate of $0.05 \mathrm{~m} / \mathrm{r}$ and a cutting depth of $0.15 \mathrm{~mm}$; and the cutting parameters of the group 5 are: a cutting speed of $746.3 \mathrm{~m} / \mathrm{min}$, a feed rate of $0.033 \mathrm{~m} / \mathrm{r}$ and a cutting depth of $0.15 \mathrm{~mm}$. Above cutting parameters are preferentially selected as corresponding cutting parameters of ZGM13 steel to increase cutting efficiency, and meanwhile to obtain excellent surface quality.

Thus it can be seen that the high-speed cutting of high manganese steel is favorable to improving the quality of the machined surface, but the cutting parameters should be optimized. According to the cutting theory, the height (Rmax) of remained area caused by geometrical factors keeps the following relationship [1]:

$$
R_{\max }=\frac{f}{\cot k_{r}+\cot k_{r}^{\prime}}
$$

Where $\mathrm{f}$ represents feed rate $(\mathrm{mm} / \mathrm{r}) ; \mathrm{kr}$ and $\mathrm{kr} /$ respectively represent the chamfer and vice angles of the cutting tools. From the formula (1), the geometric parameters are constant for selected cutting tools such as $\mathrm{kr}$ and $\mathrm{kr} /$. When the feed rate is fixed, the surface roughness value is almost stable, indicating that the production efficiency can be improved by high-speed cutting. Similarly, at the high-speed cutting condition, smaller feed rates can decrease the surface roughness, and are available to improving the surface quality. Therefore, it can be concluded that under the high-speed cutting conditions, smaller feed rates are selected to obtain higher resection rates and to improve the surface quality, and to reach the effect of high quality and high efficiency production.

\section{Surface Roughness Models}

As shown in Fig.3, the surface roughness values show linear distributions or variations along the curves. Because the surface roughness is related to many factors, and the relationships among them are complex. Therefore, the influence of error is inevitable in the course of the experiment, but the regression analysis method is a powerful tool to deal with the relationship between the variables. Hence, the regularity between the surface roughness and cutting dosages is obtained by experimental data, and analyzed by the regression analysis method. Two approaches were carried out to build models, and then compared and analyzed. Finally the validity of the two models is justified.

\section{Linear Regression Models}

The linear equations of the surface roughness values, cutting speeds and feed rates are established by the linear regression method, and corresponding data treatment is shown in Table 4 . The surface roughness, cutting speed and feed rate expressed by $\mathrm{y}, \mathrm{x} 1$, and $\mathrm{x} 2$, show the data structure of the multiple linear regression models as follows:

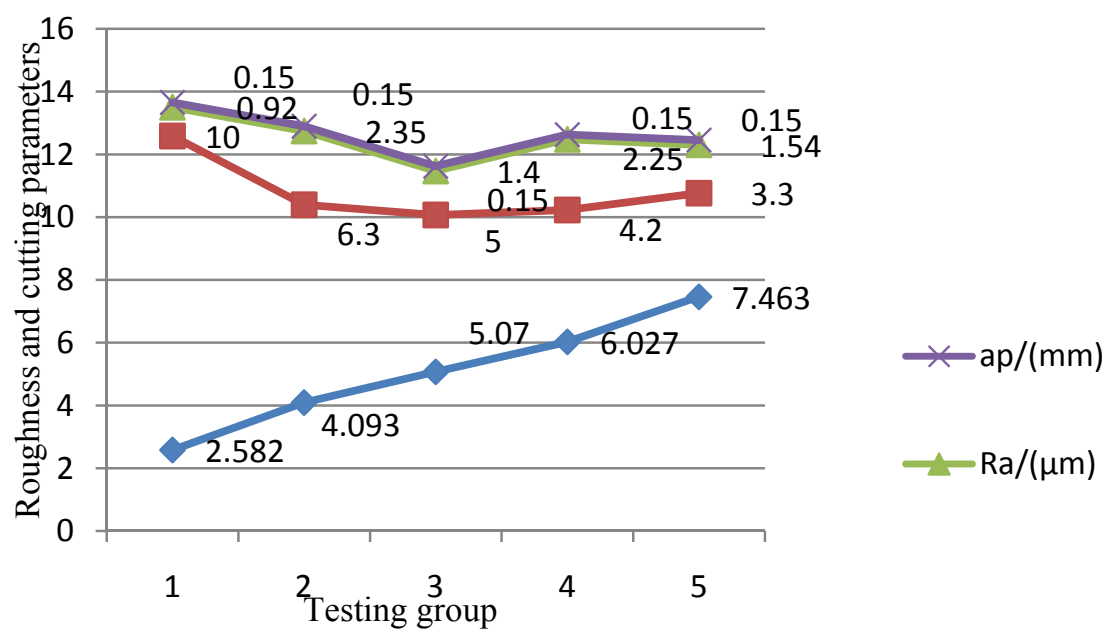

Fig.3 Effect of cutting speed and feed on roughness value 
Table 4 Experimental data and surface roughness values

\begin{tabular}{cccc}
\hline Number & \multicolumn{2}{c}{ Effect factor } & $\mathrm{y}$ \\
\cline { 2 - 3 } & $\mathrm{x}_{1}$ & $\mathrm{x}_{2}$ & $\mathrm{Ra}$ \\
1 & $\mathrm{v}_{\mathrm{c}} /(\mathrm{m} / \mathrm{min})$ & $\mathrm{f} /(\mathrm{mm} / \mathrm{r})$ & $/ \mu \mathrm{m}$ \\
2 & 258.2 & 0.1 & 0.92 \\
3 & 409.3 & 0.063 & 2.35 \\
4 & 507 & 0.05 & 1.4 \\
5 & 602.7 & 0.042 & 2.25 \\
$y_{\alpha}=\beta_{0}+\beta_{1}\left(x_{\alpha 1}-\overline{x_{1}}\right)+\beta_{2}\left(x_{\alpha 2}-\overline{x_{2}}\right)+\varepsilon_{\alpha}(\alpha=1,2, \ldots, 5)$ & 1.54 \\
\hline & 746.3 & 0.033 & \\
\hline
\end{tabular}

Where $\varepsilon \alpha$ represents experimental values, which are random variables caused by random factors; $\mathrm{y} \alpha$ represents experimental values, which is random variety caused by $\varepsilon \alpha ; \mathrm{x} \alpha 1$ and $\mathrm{x} \alpha 2$ represent the experimental cutting speed and feed rate respectively; $\bar{X}_{1}$ and $\bar{X}_{2}$ are arithmetic average values of the cutting speeds and feed rates respectively; $\beta 0$ is constant parameter; and $\beta 1$ and $\beta 2$ are coefficient parameters of the $\mathrm{x} \alpha 1$ and $\mathrm{x} \alpha 2$, respectively. The least square method is used to determine the parameters of the $\beta 0, \beta 1$ and $\beta 2$, and corresponding one element linear regression equation is:

$$
\hat{y}=\mu_{0}+b_{1}\left(x_{1}-\bar{x}_{1}\right)+b_{2}\left(x_{2}-\bar{x}_{2}\right)
$$

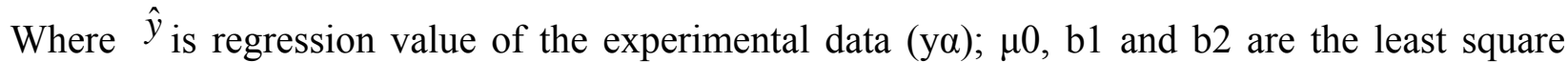
estimations of the $\beta 0, \beta 1$ and $\beta 2$ parameters respectively. The $\mu 0, b 1$ and $b 2$ values obtained by the least square method make the deviation square sums of the experimental value $(\mathrm{y} \alpha)$ and the regression value $(\hat{y})$ for the minimum value, and the regression coefficients $(\mu 0, \mathrm{~b} 1$ and b2) are obtained by combinations of Table 3 and formula (3):

$$
\left(\begin{array}{l}
\mu_{0} \\
b_{1} \\
b_{2}
\end{array}\right)=\left(\begin{array}{l}
1.728 \\
-0.00615898 \\
-52.9147
\end{array}\right)
$$

To bring $\mu 0, \mathrm{~b} 1$ and $\mathrm{b} 2$ into the formula (3), the regression equation is:

$$
\hat{y}=7.905489806-0.00615898 x_{1}-52.9147 x_{2}
$$

From the formula (3), the surface values decrease with the cutting speeds increase under high-speed cutting condition, and the surface values also decrease with the feed rates increase, but their effect weights of the roughness value are different. The conclusion is different from the theoretical roughness and formula (1) of the feed rate, which is obtained by the geometry method during the conventional cutting process. The formula (1) shows that the surface roughness increases with the feed rates increase, whereas the formula (4) reveals that to some extent increasing of feed rates is available for improving of surface quality under high-speed cutting. This indicates that the high-speed cutting shows specific deformation mechanism. 


\section{Non-linear Regression Model}

The data structure of the nonlinear regression model of the surface roughness value is following:

$$
y_{\alpha}=\beta_{0}+\beta_{1} x_{\alpha 1}^{2}+\beta_{2} x_{\alpha 2}^{2}+\varepsilon_{\alpha}(\alpha=1,2, \ldots, 5)
$$

Where $y \alpha$ is the experimental value of the surface roughness; $\beta 0$ is estimated parameter; $\beta 1$ and $\beta 2$ are the estimated parameters of coefficients of quadratic cutting speed and feed rate; $\varepsilon \alpha$ is random variable caused by random factors. Similarly, the estimated $\beta$ parameter is obtained by the least square method. The $b 0, b 1$ and $b 2$ correspond to the least square estimation of $\beta 0, \beta 1$ and $\beta 2$, and the two elemental nonlinear regression equations of the formula (5) are:

$$
\hat{y}=b_{0}+b_{1} x_{\alpha 1}^{2}+b_{2} x_{\alpha 2}^{2}
$$

The regression coefficients (b0, b1 and b2) are obtained by formula (6):

$$
\left(\begin{array}{l}
b_{0} \\
b_{1} \\
b_{2}
\end{array}\right)=\left(\begin{array}{l}
3.43061 \\
-2.95571 \times 10^{-6} \\
-224.676
\end{array}\right)
$$

To plug b0, b1 and b2 into formula (6), the two nonlinear regression equations are obtained:

$$
\hat{y}=3.43061-2.95571 \times 10^{-6} x_{1}^{2}-224.676 x_{2}^{2}
$$

\section{Comparison of Two Models .}

Formulas (4) and (7) correspond to two types of surface roughness models established by the linear and nonlinear regression theories respectively. In order to consider the efficiency and prediction accuracy of two models, the surface roughness under the same cutting conditions were estimated by two models, and the estimated values are compared with the experimental values to calculate the relative errors, which are considered as the effective basis of the models.

Table 5 shows the cutting conditions of the experiments 1 through 5, and the surface roughness values are estimated by the linear and nonlinear regression models, and the errors between the predicted and experimental values are calculated. It can be seen that the prediction values of the linear regression model are close to the experimental values, and the maximum and minimum errors between the predicted and experimental values are $12.72 \%$ and $1.48 \%$, respectively. This indicates that the prediction accuracy is reasonable as the prediction values of the nonlinear regression model are also close to the experimental values, but the prediction accuracy is worse than that of the linear model. The maximum and minimum errors between the predicted and experimental values are 13.13 , and $7.26 \%$, respectively.

According to above results, it can be found that (1) the established linear and nonlinear models of surface roughness for high-speed cutting of high manganese steels can be used to predict the surface roughness of machined samples at high-speed cutting, and prediction accuracies are relative high. Generally speaking, the calculated results of the linear model are more accuracy than those of the nonlinear model; (2) according to studied models, requirements of surface quality for the machined sample and conditions of existing machine tools, the cutting speed (vc) and feed rate (f) can provide the basis for the development of reasonable processing procedures for the high-speed cutting process. The cutting depth (ap) was selected according to the blank type, machining allowance and rigidity of process system. 
Table5 Prediction of roughness values of machined surface and its corresponding measured values

\begin{tabular}{lllll}
\hline Experimental number & 1 & 2 & 4 & 5 \\
\hline Measured value y & 0.92 & 2.35 & 2.25 & 1.54 \\
Linear regression value $\mathrm{y}_{\alpha}$ & 1.02377117 & 2.050993192 & 1.97105516 & 1.562857932 \\
Relative linear error \% & 11.28 & 12.72 & 12.4 & 1.48 \\
Nonlinear regression value & 0.986800973 & 2.043711235 & 1.960627888 & 1.337665212 \\
Relative nonlinear error \% & 7.26 & 13.0 & 12.86 & 13.13 \\
\hline
\end{tabular}

(1) Fig.4 shows the appearance and microscopic morphologies of chips at a cutting speed of $258.2 \mathrm{~m} / \mathrm{min}$, a feed rate of $0.1 \mathrm{~mm} / \mathrm{r}$ and a cutting depth of $0.15 \mathrm{~mm}$. As shown in Fig.4a, the macroscopic appearance of chips shows continuous belt-like morphology, and relatively rough surface is mainly due to relative big feed rate and thick cutting depth. As shown in Fig.4b, the bottom of the chips show burn characteristics, indicating that the temperature at tool/chip interface is very high and probably exceed to phase transformation point (about in the range of $900^{\circ} \mathrm{C} \sim$ $1000^{\circ} \mathrm{C}$ ). As shown in Fig.4c, the top of the chips shows relatively small-zigzagged morphology.

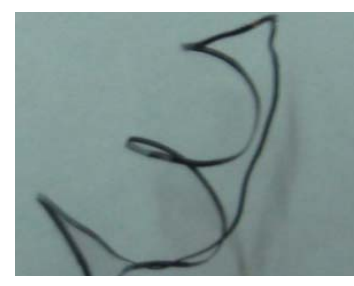

(a) chip appearance

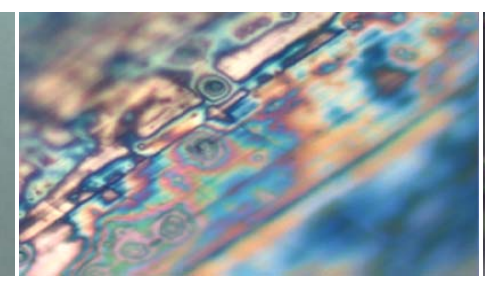

(b) chip bottom (50X)

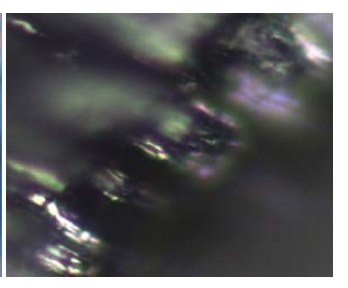

(c) chip top (50X)

Fig.4 Chip deformation at a cutting speed of $258.2 \mathrm{~m} / \mathrm{min}$, a feed rate of $0.1 \mathrm{~mm} / \mathrm{r}$ and a cutting depth of $0.15 \mathrm{~mm}$

(2) Fig.5 shows the appearance and microscopic morphologies of chips at a cutting speed of $409.3 \mathrm{~m} / \mathrm{min}$, a feed rate of $0.063 \mathrm{~mm} / \mathrm{r}$ and a cutting depth of $0.15 \mathrm{~mm}$. As shown in Fig. $4 \mathrm{a}$, the appearance of chips shows continuous belt-like morphology, but more soft and curly are mainly due to relative thin chip thickness caused by smaller feed rate. In addition, it is related to high cutting temperature caused by high cutting speed. As shown in Fig.5b, the image of the bottom of the chip shows interval burn characteristics, with a dark color, indicating that the burn degree is very severe. The main cause is that the higher cutting speed results in higher cutting temperature, and meanwhile it is related to smaller feed rate, thin cutting depth and heat concentration. As shown in Fig. $5 \mathrm{c}$, the image of the top of the chip shows zigzagged morphology, and the trend becomes more apparent, and the amplitude of zigzag increases. The dark color indicates higher cutting temperature.

(3) Fig.6 shows the appearance and microscopic morphologies of chips at a cutting speed of $506.95 \mathrm{~m} / \mathrm{min}$, a feed rate of $0.05 \mathrm{~mm} / \mathrm{r}$ and a cutting depth of $0.15 \mathrm{~mm}$. As shown in Fig.6a, the macroscopic shape first changes from rapidly belt-like morphology to aggregate morphology. This indicates that first cutting temperature is not enough high, but subsequently rapidly increases with the cutting process prolonging, resulting in softening of cutting layers. As shown in Fig.6b, the image of the bottom of the chip shows the burn characteristics of dense sheet due to high cutting temperature, which is primarily consistent with the macroscopic shape. As shown in Fig.6c, the image of the top of the chip shows the zigzagged morphology, and the zigzag spacing increases and finally reaches facture. This characteristic can be certified by macroscopic shape. 


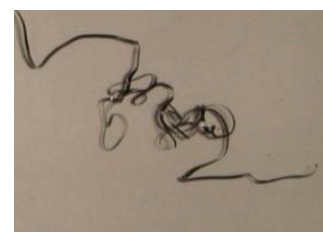

(a) appearance

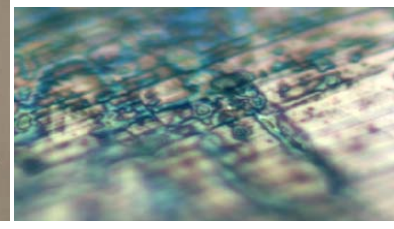

(b) chip bottom (50X)

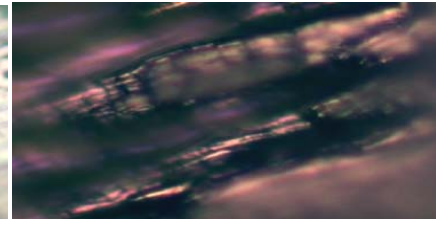

(c) chip top (50X)

Fig. 5 Chip deformation at a cutting speed of $409.3 \mathrm{~m} / \mathrm{min}$, a feed rate of $0.063 \mathrm{~mm} / \mathrm{r}$ and a cutting depth of $0.15 \mathrm{~mm}$

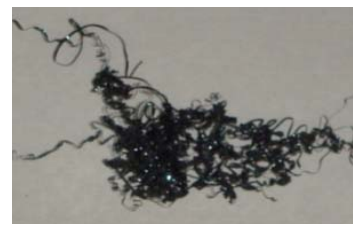

(a) chip appearance

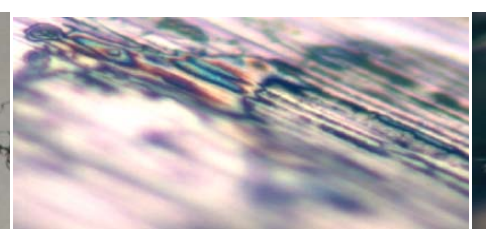

(b) chip bottom (50X)

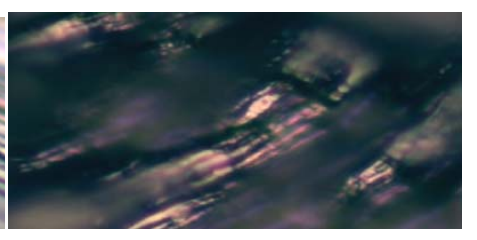

(c) chip top (50X)

Fig. 6 Chip deformation at a cutting speed of $506.95 \mathrm{~m} / \mathrm{min}$, a feed rate of $0.05 \mathrm{~mm} / \mathrm{r}$ and a cutting depth of $0.15 \mathrm{~mm}$

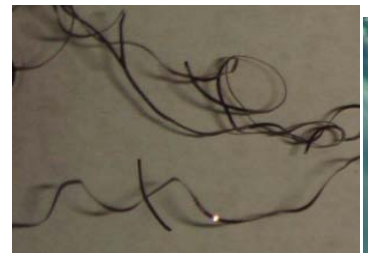

(a) chip appearance

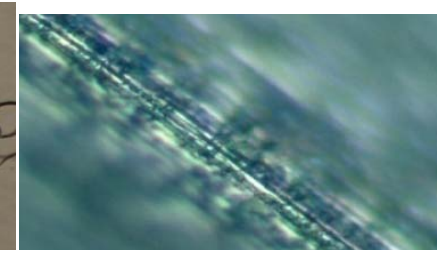

(b) chip bottom (50X)

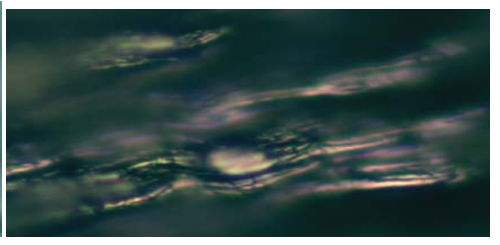

(c) chip top (50X)

Fig. 7 Chip deformation at a cutting speed of $602.69 \mathrm{~m} / \mathrm{min}$, a feed rate of $0.042 \mathrm{~mm} / \mathrm{r}$ and a cutting depth of $0.15 \mathrm{~mm}$

(4) Fig.7 shows the appearance and microscopic morphologies of chips at a cutting speed of $602.69 \mathrm{~m} / \mathrm{min}$, a feed rate of $0.042 \mathrm{~mm} / \mathrm{r}$ and a cutting depth of $0.15 \mathrm{~mm}$. As shown in Fig. $7 \mathrm{a}$, the purple-red chips show belt-like morphology and variable lengths, and Fig.7b shows deep colored chips on the bottom. This is due to the appearance of the cold-weld phenomenon occurring in chips caused by high temperature and high pressure, and built-up edges fractured by moving chips. As shown in Fig.7c, peak and valley characteristics with high and low fluctuations appear in chip top, similar to the zigzagged morphology, but the zigzag feature is not obvious relative to Fig.6c.

(5) Fig.8 shows the appearance and microscopic morphologies of chips at a cutting speed of $746.3 \mathrm{~m} / \mathrm{min}$, a feed rate of $0.033 \mathrm{~mm} / \mathrm{r}$ and a cutting depth of $0.15 \mathrm{~mm}$. As shown in Fig. $8 \mathrm{a}$, the chip appearance shows flake shape, notably different from that of chip appearances. This indicates that the length of cut chips is very short at high-speed cutting condition, and significant changes have occurred in the chip shape, showing the changes from long belt-like morphology to short belt-like or C-shaped morphology. As shown in Fig.8b, it can be seen that the bottom of the chip is extremely rough, indicating that the chips seriously deform. The lower part of the surface temperature of the chip is high, and generates severe cold-weld cutting phenomenon, which is a typical bond effect, resulting in the coarse cutting surface. As shown in Fig.8c, it can be seen that zigzagged degree is very obvious. This certifies that the zigzagged chips are typical feature of high-speed cutting.

From the chip appearances as shown in Fig.4a through Fig.8a, it can be found that the chip shape changes from the continuously long belt-like morphology to easily broken short morphology with the cutting speeds increase, and finally transforms to broken short chips. This indicates that considerable changes have occurred in the deformation mechanism at high-speed cutting conditions. This is mainly due to the combinations of work hardening and high temperature softening. On the other hand, under high-speed cutting, the cutting layer material is subjected to rapid and intense extrusion and deformation of the cutting edge from the cutting blades. This is equal to the work hardening caused by high-speed impact, resulting in decreasing of the material plasticity of the shear slip surface, increasing of brittleness and improving hardness. Moreover, shear sliding speed 
increases under high cutting speed, and the deformation process is very rapid. Hence most deformation energy of cutting layers transforms into the cutting heat. In addition, the thermal conductivity of the high manganese steels is low, and heat is not timely spread, and results in easily appearances of shear slip. The whole process is called as softening effect. In addition, higher cutting speeds lead to the increase of flow speeds in chips, in association with the high manganese steel material with good plasticity and toughness. Therefore, even in the case of high-speed cutting, the deformation hardening effect is not easy to make the chips appear naturally macro brittle fracture, so most chips show belt-like morphology at high-speed cutting ranges. Only when the cutting speed reaches a critical value, the hardening and softening effects exist at the same time, and the chips trend to break when the hardening effect is dominant as shown in Fig.8a.

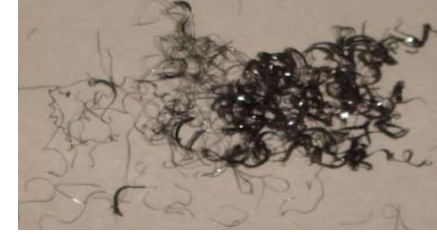

(a) chip appearance

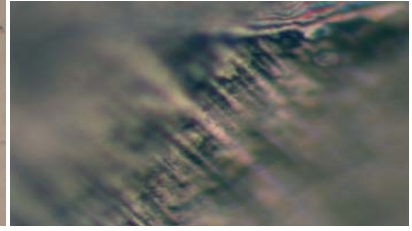

(b) chip bottom (50X)

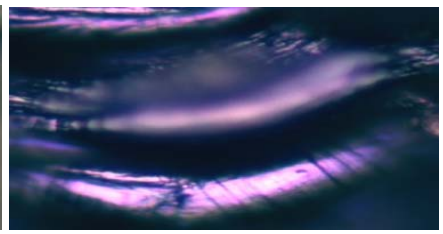

(c) chip top (50X)

Fig. 8 Chip deformation at a cutting speed of $746.3 \mathrm{~m} / \mathrm{min}$, a feed rate of $0.033 \mathrm{~mm} / \mathrm{r}$ and a cutting depth of $0.15 \mathrm{~mm}$

From the appearances of the bottom of the chip as shown in Fig. $4 \mathrm{~b}$ through Fig.8b, it can been found that the chips flow out along the rake face at relative high cutting speed, and the rake face temperature is higher because of extrusion and sliding friction heat. The bottom of the surface of the chips is burned under high temperature, showing burn color. With the cutting speeds increase, the burn color become more and more deep; under higher cutting speeds, the interfaces between the tools and chips affect bond effect, and the trend increases with the cutting speeds increase. The bottom of the chips shows coarse faces due to irregular fracture of built-up edges.

From the appearances of the top of the chip as shown in Fig.4b through Fig.8b, it can be found that the little-zigzagged shapes are observed at high cutting speeds. However, when the experimental cutting speed reaches the maximum value $(746.3 \mathrm{~m} / \mathrm{min})$, the cracks can occur. From the appearances of the top of the chips as shown in Fig.4b through Fig.8b, it can been found that high-speed cutting of high manganese steel shows microscopic zigzagged shape occurring in chip top; with the cutting speeds increase, the zigzagged trend is more pronounced; when the experimental cutting speed reaches the maximum value $(746.3 \mathrm{~m} / \mathrm{min})$, zigzag of chips confronts verge of breaking.

\section{Conclusions}

Metal ceramic cutting tools (RCHT01) were performed to high-speed cut high manganese steel (ZGMn13), and the deformation mechanisms of high-speed cutting and surface quality were studied. The following conclusions are obtained:

(1) The cutting parameters have remarkable influence on the surface roughness of machined samples during the high-speed cutting processes. The feed rate has the greatest influence, and the cutting speeds have a relatively significant influence. The reduction of feed rate decreases the surface roughness, but the rigidity of the technology system and the property of tool material are good, the increase of the cutting speeds can decrease surface roughness values. In theory, the effect of cutting depth on surface roughness is ignored, but in fact the increment of cutting depth results in increasing of radius force, leading to the vibration of cutting tools and further increasing of surface roughness value.

(2) The deformation processes of high manganese steel materials are affected and controlled by work hardening and softening effects at dry and high-speed cutting. The work hardening effect is related to the cutting layer materials which undergo the severe extrusion between the nose radius 
and cutting edge blunt round radius as well as the flank friction during the high-speed cutting. The plastic deformation of materials results in increasing of hardness, reduction of plasticity, and increasing of brittleness; the softening effect is related to transformation of most energy of high-speed cutting consumption to cutting heat, which generates extremely high temperature of cutting deformation zones, resulting in rapidly softening of material and reducing of strength. Across the shear deformation zone, the temperature rapidly decreases due to the top surface of free surface, which causes high thermal stress and further produces micro-cracks. The shear slip deformation of chips rapidly occurs and then rapidly stops, resulting in layer and layer stacking. Therefore, macroscopic images of the belt-like chips show zigzagged appearances on top surface.

(3) The bottom surface of chips shows burn color and coarse stage. The burn color is related to high temperature zones caused by friction heat at the tool/chip interfaces and deformation heat; The coarse bottom surface of chips is related to fractured built-up edges on the rake face.

(4) The prediction accuracy of surface roughness model is up to $87.28 \% \sim 98.52 \%$. Conversely, the model can be used to obtain cutting speed and feed rate at high-speed cutting.

\section{Acknowledgements}

The authors are grateful to the Natural Science Foundation of Gan-Su Province, China (Grant no. 145RJZA134) and the Science Technology Program of Lan-Zhou City, Gan-Su Province, China (Grant no. 2015-3-99) and Lan-Zhou City University President Science and Research Innovation Foundation (Grant no. LZCU-XZ2014-01) for financial support in this investigation.

\section{References}

[1] L.Y. Gu, M.J. Wang. Predicttion of Adiabatic Shear Localization Fracture in High Speed Machining [J]. Journal of Mechanical Engineering, 2016, 52(5) : (186-192).

[2] D.C, M. Wang, J. Pang, et al. A calculational model of shear strain and strain rate within shear band in a serrated chip formed during high speed machining [J]. J. Mater. Process Tech., 2006, 178(1-3): 274-277.

[3] N. He, T. Lee, W. Lau, et al. Assessment of deformation of a shear localized chip in high speed machining [J]. Journal of Materials Processing Tech., 2002, 129(1-3): 101-104.

[4] G.H. L, M.J. W, C.Z. D. Adiabatic shear critical condition in the high-speed cutting [J]. J. Mater. Process Tech., 2009, 209(3): 1362-1367.

[5] L. H. TANG, J. L. Huang, C. X. Gao, et al. Surface roughness test and prediction model of turning harden tool steel $\mathrm{Cr} 12 \mathrm{MoV}$ in dry-type[J].Journal of Lanzhou University of Technology,2012(4): 34-36.

[6] S. Dilbag, P. V. Rao. A surface roughness prediction model for hard turning process [J]. Int J Adv Manuf Technol, 2007, 32: 1115-1124.

[7] H.P. An, Z.Y. Rui, R.F. Wang, et al. Research on cutting-temperature field and distribution of heat rates among a workpiece, cutter, and chip for high-speed cutting based on analytical and numerical methods [J]. Strength of Materials, Vol. 46, No. 2, March, 2014: 289-295.

[8] H.P. An, Z.Y. Rui, J.F. Guo, et al. Wear Mechanism of Coated Tool During High Speed Mechining [J]. 2010 International Conference on Digital Manufacturing \& Automation, IEEE.18-20 December 2010, pp 913-918.

[9] H.P. An, Z.Y. Rui, R.F. Wang, et al. A New Method on Choosing Tool Materials at High Speed Machining [C]. Materials Processing Technology [J]. The 2nd International Conference on Advanced Design and Manufacturing Engineering, 2011, pp 745-749.

[10] H.P. An, Z.Y. Rui, R.F. Wang, et al. Deformation of Serrated Chips Based on Minimum Energy Consumed for High Speed Machining [J].The 2nd international conference on advanced design and manufacturing engineering, Advanced Materials and Process Technology, 2012,Vols.217-219, pp1609-1613. 
[11] H.P. An, Z.Y. Rui, R.F. Wang. Model of Shear Slipping Deformation and It's Cutting Energy Consumed for High Speed Machining [J]. The 2nd International Conference on Materials and Products Manufacturing Technology, 2012, pp1667-1970.

[12] H.P. An, Z.Y. Rui, X. Li. Research on geometrical model and mechanism for metal deformation based on plastic flow (J). 4th Global Conference on Materials Science and Engineering, 2015, (1-8).

[13] H.P. An, Z.Y. Rui, R.F. Wang. Research on a mechanism for measuring force in material moulding and the features of its measuring circuits (C). Electronics and Electrical Engineering Proceedings of the Asia-Pacific Conference on Electronics and Electrical Engineering, EEEC 2014, Issue date: 2015, pp351-354.

[14] C. Madalina, C. Dominique, G. Franck. A new material model for 2D numerical simulation of serrated chip formation when machining titanium alloy $\mathrm{Ti}-6 \mathrm{Al}-4 \mathrm{~V}[\mathrm{~J}]$. International Journal of Machine Tools \& Manufacture 48 (2008) 275-288.

[15] G. Sutter. Chip geometries during high-speed machining for orthogonal cutting conditions [J]. International Journal of Machine Tools \& Manufacture 45 (2005) 719-726. 